\title{
A HYDROSTATIC WEIGHING METHOD USING TOTAL LUNG CAPACITY AND A SMALL TANK
}

\author{
J. G. WARNER, Jr., MS, Rachel YEATER, PhD, Lauralee SHERWOOD, DVM and K. WEBER, PhD
}

Human Performance Laboratory, West Virginia University, Morgantown, West Virginia 26506

\section{ABSTRACT}

The purpose of this study was to establish the validity and reliability of a hydrostatic weighing method using total lung capacity (measuring vital capacity with a respirometer at the time of weighing) the prone position, and a small oblong tank. The validity of the method was established by comparing the TLC prone (tank) method against three hydrostatic weighing methods administered in a pool. The three methods included residual volume seated, TLC seated and TLC prone. Eighty male and female subjects were underwater weighed using each of the four methods. Validity coefficients for per cent body fat between the TLC prone (tank) method and the RV seated (pool), TLC seated (pool) and TLC prone (pool) methods were .98, .99 and .99, respectively. A randomised complete block ANOVA found significant differences between the RV seated (pool) method and each of the three TLC methods with respect to both body density and per cent body fat. The differences were negligible with respect to HW error. Reliability of the TLC prone (tank) method was established by weighing twenty subjects three different times with ten-minute time intervals between testing. Multiple correlations yielded reliability coefficients for body density and per cent body fat values of .99 and .99 , respectively. It was concluded that the TLC prone (tank) method is valid, reliable and a favourable method of hydrostatic weighing.

Key words: Hydrostatic weighing, Body density, Per cent body fat, Total lung capacity, Vital capacity, Residual volume.

\section{INTRODUCTION}

Along with the growing interest in physical fitness, an interest in body composition has also evolved. The use of body fat percentage has proven to be a useful tool in determining optimal weights for individuals.

Hydrostatic weighing (HW) is the most valid method of estimating body fat other than the actual determination of fat from cadavers. There are a variety of methods for weighing, each with certain limitations. It is imperative to have a method that provides both valid and reliable results; however, it is also important to have a method that is comfortable for the subject. The most controversial issues of hydrostatic weighing involve choice of lung volume and body position. The question of whether lung volumes should be assessed in or out of the water also merits further attention.

Residual volume (RV) is the lung volume most commonly used for determination of body density through hydrostatic weighing. Welch and Crisp (1958) determined that residual volume (RV) is the lung volume least affected by hydrostatic pressure. Goldman and Buskirk (1961), in describing procedures for hydrostatic weighing, recommended that the subject bend forward at the waist and expire to end expiration at which time the scale was read. Katch et al (1967) felt that the devices and methods for weighing described by Goldman and Buskirk (1961) were both expensive and difficult to maintain and therefore devised a simpler method: The apparatus was built to fit in the shallow end of a swimming pool. Subjects were weighed in the prone position for nine to ten trials with the average of the last three trials being used as the "true" underwater weight.

Thomas and Cook (1978) devised a similar method for hydrostatic weighing. Instead of a swimming pool, the subjects were weighed in the prone position in a large, oblong livestock tank. Residual volume was estimated from vital capacity (VC) measurements (Wilmore, 1969b) using the formulas $R V=0.24 \times$ VC for men and $R V=0.28 \times V C$ for women. The underwater weight was determined from the mean of the last five of ten trials.

Maximum expiration to the point of residual volume is a difficult technique, especially for individuals performing the task for the first time. With this in mind, several studies have been devoted to the task of finding a more comfortable lung volume for hydrostatic weighing that is comparable to the methods that utilise RV.

Welch and Crisp (1958) compared body density measurements between maximum expiration and approximately one-half maximum expiration. A significant difference was found when comparing density units derived from the two lung volumes. The average density following maximum expiration was 0.0017 density units lower than the average density following one-half maximum expiration. It was concluded that lung volumes at one-half expiration were affected by hydrostatic pressure; therefore, body density should be measured following maximum expiration. The oxygen flush-out technique devised by Cournand et al (1941) was used to determine residual volume. However, recent evidence has shown that the measurement of RV by dilution techniques during immersion may be inaccurate (Dahlback and Lungren, 1972). Robertson et al (1978) compared dilution and plethysmographic techniques and discovered that the dilution method underestimated residual volume by about $200 \mathrm{ml}$ when the subject was submerged. Trapped air behind closed airways was assumed to be the cause of underestimation. This trapped air was not detected by the dilution method. Thomas and Etheridge (1980) suggested that the density determined from approximately one-half expiration by Welch and Crisp (1958) may be more accurate than the density determined from residual volume due to the gas trapping error.

Thomas and Etheridge (1980) compared body density measurements at RV and functional residual capacity (FRC). Lung volumes were measured by a helium dilution technique (Braintree, 1967) while the subject was submerged and in the prone position. The results showed a negligible difference between per cent fat determinations by this technique and residual volume. It was therefore suggested that body density determinations from hydrostatic weighing at functional residual capacity are favourable when lung volumes can be measured during underwater weighing due to increased comfort for the subject.

The use of total lung capacity (TLC) as a lung volume for hydrostatic weighing would eliminate the problem of gas trapping (Dahlback and Lungen, 1972; Prefaut et al, 1976). Weltman and Katch (1981) compared hydrostatic weighing at residual volume and total lung capacity. There was a small but statistically significant difference in body density; however, the differences between per cent fat determina- 
tions by hydrostatic weighing at residual volume and total lung capacity were negligible. The use of total lung capacity or functional residual capacity may eliminate the need for repeated underwater weighing trials because there is a smaller learning process than there is in weighing at residual volume.

Posture is another element that must be considered when determining body density. Changes in lung volumes during recumbency occur due to the elevation of the level of the diaphragm and the increase in the amount of blood reaching the pulmonary circulation (Whitfield et al, 1950) who compared lung volumes in the sitting and lying positions. The results showed a decrease in the TLC, VC, FRC, and RV during recumbency. In a more recent study, Etheridge and Thomas (1978) reported significantly lower FRC, VC, and TLC while prone on land than while seated on land. However, RV was not significantly altered by body position. Although the traditional methods of hydrostatic weighing involves weighing the subject in a seated position, numerous studies have utilised the prone position with valid results (Katch et al, 1967; Thomas and Cook, 1978; Thomas and Etheridge, 1980).

Although various lung volumes, body positions and apparatus have been employed in past research there has not been a study that combined total lung capacity in the prone position with the use of a small tank. The purpose of this study was to establish the validity and reliability of a method of hydrostatic weighing which combines: (1) maximum comfort for subjects (total lung capacity and the prone position) (2) inexpensive apparatus that requires minimal space so that even small laboratories could incorporate its use (small livestock tank) and (3) a method that is accurate and simplistic (use of a respirometer during weighing and the oxygen dilution technique for residual volume).

\section{METHODS}

\section{Subjects}

The subjects in this study were male $(N=42)$ and female $(N=38)$ volunteers ranging from ages $18-35$ years with a mean age of 22.1 years. Two subgroups $(N=20$ for each group) were used to establish the reliability of the procedure. All were required to sign an informed consent statement (approved by the West Virginia University institutional review board for the protection of human subjects) and the procedures followed guidelines for use of human subjects suggested by the American College of Sports Medicine.

For all tests, the subjects were instructed to report to the appropriate area dressed in bathing attire, and were told to refrain from eating or drinking anything for at least four hours prior to testing. They were also asked to expel any gas or faeces from the bowels and to urinate before reporting to the lab. Dry weight in bathing attire was obtained on a scale and recorded prior to testing.

\section{EQUIPMENT}

\section{Residual Volume}

Breathing took place while connected to a " $T$ "-shaped stopcock (Warren E. Collins, Inc.) and a five-litre anaesthesia bag manufactured by For-Last. The bags were initially filled with $\mathbf{9 9 . 9 9 3 \%}$ oxygen manufactured by Airco Specialty Gases. The volume of oxygen was measured with a combination flow meter and regulator (Victor Welding Products; Medical Division). The oxygen and carbon dioxide content of the air samples were measured by a Beckman OM-11 Polargraphic Analyser and a Beckman LB-2 Infrared Analyser, respectively. The oxygen analyser was calibrated to room air $\left(20.9 \% \mathrm{O}_{2}\right)$ and the carbon dioxide analyser was calibrated to $10 \%$ using certified gas.

\section{Hydrostatic Weighing}

Dry body weight was measured on a Health-O-Meter Scale manufactured by Continental. In the diving area, weighing took place on an aluminium tare swing $60^{\prime \prime} \times 37^{\prime \prime}(150 \times 95$ cms approx.) for the prone position and a rope swing 53 " $\times 251 / 2$ " (135 $\times 64 \mathrm{cms}$ approx.) for the seated position. Underwater weight was measured on a Chatillon Scale $(15 \mathrm{~kg} \times 25 \mathrm{~g})$. The swings and scale were supported by a wooden horse 168 " $\times 49^{\prime \prime}(425 \times 125 \mathrm{cms}$ approx.). In the Human Performance Laboratory, weighing took place in a galvanised tank 120" $\times 37^{\prime \prime} \times 24 "(300 \times 94 \times 60 \mathrm{cms}$ approx.). The aluminium tare swing was used for weighing in the prone position and underwater weight was measured on the Chatillon Scale. The swing and scale were supported by a wooden horse $70^{\prime \prime} \times 48$ " (178 $\times 122 \mathrm{cms}$ approx.). Forced vital capacity was measured using a Warren $E$. Collins, Inc. 13.5-litre capacity respirometer. Water temperature was measured with a Bi-Therm Dial Thermometer manufactured by Taylor Instrument Company.

\section{Hydrostatic Weighing Methods to Determine Validity}

Residual volume seated. The subjects reported to the diving area of the Natatorium. They submerged themselves completely in the water, making sure any air bubbles were eliminated from the body and bathing suits, then sat on the rope sing so they were immersed to the neck. A weighted belt (10-20 lbs) was placed around the waist to ensure proper submersion. A rope was attached to the belt for safety purposes in case a subject fell from the swing. While connected to a respirometer, forced vital capacity was then determined by having the subjects hold their noses, inhale as much as possible, and then exhale fully. Two or more trials were administered until the readings were within one $\mathrm{mm}$. Forced vital capacity was converted to $\mathrm{ml}$ by multiplying the $\mathrm{mm}$ reading by $\mathbf{4 1 . 2 7}$ which was the conversion factor for the Collins Respirometer, and was corrected to BTPS. Forced vital capacity and the respirometer temperature were recorded. During the entire breathing procedure the subjects were encouraged by the experimenter to inspire and expire as much as possible. Residual volume was then determined using a closed circuit oxygen dilution technique (Wilmore, 1980). This simplified method was used because it was portable, it can be used during hydrostatic weighing, and it can be completed in five minutes or less. With this method, a five litre anaesthesia bag was flushed three times with oxygen and filled with $90 \%$ of the subject's forced vital capacity. The subjects were connected to the bag via a "T"-valve and were instructed to exhale maximally to the point of residual volume. At the end of the expiration, the " $T$ "-valve was turned so the subjects could breathe the oxygen. They then took seven deep breaths at a rate of approximately one breath every two seconds. On the seventh breath, they exhaled to the point of residual volume and the bag was closed, and analysed for oxygen and carbon dioxide content. Residual volume was calculated using the formula RV $=\left(\mathrm{VO}_{2} \times \mathrm{b}\right) /\left(79.8-\mathrm{b}\right.$ where $\mathrm{VO}_{2}$ was the volume of oxygen in the bag at the beginning of the procedure and $\mathbf{b}$ was the per cent of nitrogen in the mixed air in the bag at the point of equilibrium $\left[100 \%-1 \% \mathrm{O}_{2}+\right.$ $\left.\%\left(\mathrm{CO}_{2}\right)\right]$. This method was found to be both reliable $(r=0.99)$ and valid $(r=0.92)$ when compared with an established oxygen dilution technique (Wilmore, 1969a). After residual volume determination, subjects were then connected to the respirometer and while holding their noses, they performed a maximum inspiration followed by a maximum expiration. At the end of expiration, the respirometer tube was removed from the mouth. They then held their breath and bent forward so that they were completely submerged. Underwater weight was read and recorded. At least two trials were performed for consistency or until the forced vital capacity measurements were within one $\mathrm{mm}$ of the predetermined level. Forced vital capacity was determined during the residual volume technique to 
ensure that the subject was exhaling enough. Forced vital capacity and respirometer temperatures were recorded, and subjects then left the rope swing and the tare weight and water temperature were recorded.

Total lung capacity seated. The subjects were seated on a rope swing in the diving area of the Natatorium. A weighted belt was placed around the waist to immerse them to the neck. Forced vital capacity and residual volume were determined utilising the same procedures as previously described. While holding their nose, they then performed a maximum expiration followed by maximum inspiration. When the lungs were filled completely, the hose was removed from the mouth, the breath held and they submerged completely. Underwater weight was read and recorded. At least two trials were performed or until the forced vital capacity readings were within one $\mathrm{mm}$ of the predetermined level. Forced vital capacity and respirometer temperatures were recorded. The subjects then left the rope swing, and the tare weight and water temperature were recorded.

Total lung capacity prone. Total lung capacity in the prone position was administered in the diving area of the Natatorium and in a small oblong tank in the Human Performance laboratory. Subjects were instructed to lie on their stomachs on the aluminium swing, and forced vital capacity and residual volume were determined using the same procedures as discussed in the residual volume seated section. The subjects were then connected to the respirometer, and while holding their noses they performed a maximum expiration followed by a maximum inspiration. When the lungs were full, the hose was removed from the mouth. They then held the breath and submerged completely. A sufficient weight of $10-20 \mathrm{lbs}$ (4-8 $\mathrm{kg}$ approx.) was placed on the back to ensure complete immersion. The scale was then read and the underwater weight recorded. At least two trials were performed or until the forced vital capacity at the time of weighing was within one $\mathrm{mm}$ of its predetermined value. Forced vital capacity and the respirometer temperature were recorded, and subjects were then instructed to leave the swing, and the tare weight and water temperature were recorded.

\section{Hydrostatic Weighing Methods to Determine Reliability}

Subjects were weighed underwater in the small tank in the Human Performance Laboratory using the procedures for total lung capacity in the prone position. They performed three trials with ten minute time intervals between each trial. Data were recorded for each trial.

\section{RESULTS}

Validity of the Total Lung Capacity Prone Tank Method Against Three Hydrostatic Weighing Methods

Validity coefficients were calculated for the total lung capacity prone tank method against the residual volume seated, total lung capacity seated and total lung capacity prone methods which were administered in a pool. Correlations were calculated for the following variables: per cent body fat (\%), body density $(\mathrm{g} / \mathrm{ml})$, forced vital capacity (ml), residual volume $(\mathrm{ml})$ and total lung capacity $(\mathrm{ml})$. Brozeck's formula (Brozeck et al, 1963) was used for calculating per cent body fat. Table I summarises the results of the statistical analysis.

A randomised complete block ANOVA was conducted on the four hydrostatic weighing methods to determine if there were any significant differences between the methods. The following variables were analysed: per cent body fat (\%). body density $(\mathrm{g} / \mathrm{ml})$, forced vital capacity $(\mathrm{ml})$, residual volume $(\mathrm{ml})$ and total lung capacity $(\mathrm{ml})$. Significant differences were found on all of the variables. Duncan's new multiple range test was employed to determine where the differences occurred. Table III summarises the ANOVA results. For per cent body fat, there was a significant difference between the residual volume seated pool method and each of the three total lung capacity methods. There were no significant differences between any of the latter three methods. For residual volume, there were significant differ-

TABLE I

Total Lung Capacity (TLC) Prone (Tank) vs. Residual Volume (RV) Seated (Pool), TLC Seated (Pool), TLC Prone (Pool) Validity Coefficients

\begin{tabular}{|c|c|c|c|c|c|c|c|c|c|c|}
\hline & \multicolumn{5}{|c|}{$\begin{array}{l}\text { TLC Prone (tank) } \\
\quad \mathbf{N}=80\end{array}$} & \multicolumn{5}{|c|}{$\begin{array}{l}\text { RV Seated (pool) } \\
\qquad \mathbf{N}=80\end{array}$} \\
\hline & $\begin{array}{l}\text { Fat } \\
\%\end{array}$ & $\begin{array}{l}\text { Density } \\
\mathrm{g} / \mathrm{ml}\end{array}$ & $\begin{array}{l}\text { FVC } \\
\mathrm{ml}\end{array}$ & $\begin{array}{l}\text { RV } \\
\mathrm{ml}\end{array}$ & $\begin{array}{c}\text { TLC } \\
\mathrm{ml}\end{array}$ & $\begin{array}{l}\text { Fat } \\
\%\end{array}$ & $\begin{array}{l}\text { Density } \\
\text { g/ml }\end{array}$ & $\begin{array}{l}\text { FVC } \\
\mathrm{ml}\end{array}$ & $\begin{array}{l}\text { RV } \\
\mathrm{ml}\end{array}$ & $\begin{array}{l}\mathrm{TLC} \\
\mathrm{ml}\end{array}$ \\
\hline $\bar{x}$ & 15.44 & 1.0638 & 4687 & 1093 & 5780 & 16.34 & 1.0617 & 4328 & 1134 & 5462 \\
\hline SD & 6.99 & 0.0172 & 910 & 356 & 1183 & 7.03 & 0.0174 & 838 & 368 & 1109 \\
\hline SEM & 0.78 & 0.0019 & 102 & 40 & 132 & 0.79 & 0.0019 & 94 & 41 & 124 \\
\hline \multirow[t]{2}{*}{$r^{*}$} & 0.99 & 0.98 & 0.94 & 0.95 & 0.98 & & & & & \\
\hline & \multicolumn{5}{|c|}{$\begin{array}{l}\text { TLC Prone (tank) } \\
\qquad \mathbf{N}=\mathbf{8 0}\end{array}$} & \multicolumn{5}{|c|}{$\begin{array}{l}\text { TLC Seated (pool) } \\
\qquad N=80\end{array}$} \\
\hline$\overline{\mathbf{x}}$ & 15.44 & 1.0638 & 4687 & 1093 & 5780 & 15.47 & 1.0639 & 4436 & 1134 & 5570 \\
\hline SD & 6.99 & 0.0172 & 910 & 356 & 1183 & 7.09 & 0.0176 & 858 & 368 & 1148 \\
\hline SEM & 0.78 & 0.0019 & 102 & 40 & 132 & 0.79 & 0.0020 & 96 & 41 & 128 \\
\hline \multirow[t]{2}{*}{$r^{* *}$} & 0.99 & 0.99 & 0.99 & 0.95 & 0.99 & & & & & \\
\hline & \multicolumn{5}{|c|}{$\begin{array}{l}\text { TLC Prone (tank) } \\
\qquad \mathbf{N}=\mathbf{8 0}\end{array}$} & \multicolumn{5}{|c|}{$\begin{array}{l}\text { TLC Prone (pool) } \\
\qquad N=80\end{array}$} \\
\hline $\bar{x}$ & 15.44 & 1.0638 & 4687 & 1093 & 5780 & 15.55 & 1.0637 & 4525 & 1122 & 5647 \\
\hline SD & 6.99 & 0.0172 & 910 & 356 & 1183 & 7.02 & 0.0174 & 868 & 378 & 1152 \\
\hline SEM & 0.78 & 0.0019 & 102 & 40 & 132 & 0.78 & 0.0019 & 97 & 42 & 129 \\
\hline$r+$ & 0.99 & 0.99 & 0.99 & 0.96 & 0.99 & & & & & \\
\hline
\end{tabular}

*TLC vs. RV data

**TLC vs. TLC data

+TLC vs. TLC data 
ences between the seated methods and the total lung capacity prone tank method as well as between the prone pool method and the prone tank method. There were no significant differences between the seated methods and the prone pool method. There were significant differences between all of the methods for both forced vital capacity and total lung capacity.

\section{Reliability of the Total Lung Capacity Prone Tank Method}

The reliability of this method was obtained by weighing the twenty subjects three times with ten-minute time intervals between each weighing. A multiple correlation coefficient was used to determine the reliability of the total lung capacity prone tank method. The results of the first weighing were used as the criterion variable. Correlations $\left(R_{1.23}\right)$ were obtained on per cent body fat $(\%)$ and body density $(\mathrm{g} / \mathrm{ml})$. Table II summarises the reliability results.

TABLE II

Reliability of Total Lung Capacity Prone (tank) Reliability Coefficients

\begin{tabular}{|c|c|c|c|c|c|c|}
\hline & \multicolumn{2}{|c|}{$\begin{array}{l}\text { Weighing } 1 \\
N=20\end{array}$} & \multicolumn{2}{|c|}{$\begin{array}{c}\text { Weighing } 2 \\
N=20\end{array}$} & \multicolumn{2}{|c|}{$\begin{array}{l}\text { Weighing } 3 \\
N=20\end{array}$} \\
\hline & $\begin{array}{c}\text { Fat } \\
\%\end{array}$ & $\begin{array}{c}\text { Density } \\
\mathrm{g} / \mathrm{ml}\end{array}$ & $\begin{array}{c}\text { Fat } \\
\%\end{array}$ & $\begin{array}{l}\text { Density } \\
\mathrm{g} / \mathrm{ml}\end{array}$ & $\begin{array}{l}\text { Fat } \\
\%\end{array}$ & $\begin{array}{c}\text { Density } \\
\text { g/ml }\end{array}$ \\
\hline $\bar{x}$ & 12.31 & 1.0717 & 12.29 & 1.0718 & 12.30 & 1.0717 \\
\hline SD & 6.27 & 0.0156 & 6.28 & 0.0157 & 6.30 & 0.0157 \\
\hline SEM & 1.40 & 0.0035 & 1.40 & 0.0035 & 1.41 & 0.0035 \\
\hline$R_{1.23}$ & 0.99 & 0.99 & & & & \\
\hline
\end{tabular}

\section{Comfort of the Hydrostatic Weighing Methods}

After the subjects were weighed, they were asked which method was the most comfortable. Results indicated that 61 subjects preferred total lung capacity prone, 19 preferred total lung capacity seated, while none preferred residual volume seated.

\section{DISCUSSION}

The validity of the total lung capacity prone tank method was established primarily by comparing the per cent body fat $(\%)$ values of the method with three hydrostatic weighing methods administered in a pool. Validity coefficients derived from per cent body fat values were all .98 or higher. All of the correlations were highly significant $(p<.01)$. The correlations between hydrostatic weighing at residual volume and at total lung capacity were similarly high in a study by Weltman and Katch (1981).

The correlation coefficient for the total lung capacity prone tank: forced vital capacity measurements against the residual volume seated pool: forced vital capacity measurements was lowest at .94 . This could be due to subjects being apprehensive about going under the water at residual volume and thus not exhaling enough air. The high correla- tions between total lung capacity prone tank: forced vital capacity measurements and both the total lung capacity seated pool $(r=.99)$ and total lung capacity prone pool $(r=.99)$ : forced vital capacity measurements may be due to the subjects being more at ease with total lung capacity. Mean forced vital capacity was highest for the total lung capacity prone (tank) method at $4687 \mathrm{ml}$. A possible explanation for the higher mean forced vital capacity value could involve the subjects being more comfortable in a small tank where they can put their hands on the bottom to help force more air in and out. The mean residual volume was highest for the total lung capacity seated pool and residual volume seated pool methods at $1134 \mathrm{ml}$ as compared with $1093 \mathrm{ml}$ for the total lung capacity prone tank method and $1122 \mathrm{ml}$ for the TLC prone pool method. The higher residual volume values for the seated position are in agreement with Whitfield et al (1950). The correlation coefficient for the total lung capacity measurements between the prone tank method and residual volume seated pool method was the lowest, although it was highly significant Again, the lower correlation could be due to the lower total lung capacity values for the residual volume seated pool method as a result of apprehension.

The high reliability coefficients of the total lung capacity prone tank method may be due to several factors involved in the method. The use of a respirometer to determine the exact amount of air inhaled at the time of weighing may enhance close duplicate measurements. The use of total lung capacity may also enhance the reliability because the subjects can hold their breath longer and submerge slowly. The slow submersion allows less water movement and thus smaller scale fluctuation allowing the experimenter to read the scale accurately.

A randomised complete block ANOVA was run on all four hydrostatic weighing methods for per cent body fat, body density, forced vital capacity, residual volume and total lung capacity. There were significant differences between the residual volume seated pool method and each of the three total lung capacity methods when per cent body fat was evaluated. There were no significant differences between any of the lung capacity methods with respect to per cent body fat. The mean per cent body fat value was highest for the residual volume seated pool method at $16.34 \%$ as compared with $15.44 \%$ for the total lung capacity prone tank method, $15.47 \%$ for the total lung capacity seated pool method and $15.55 \%$ for the total lung capacity prone pool method. Although mean per cent body fat values were significantly different when the residual volume seated pool method was compared with the total lung capacity methods, the differences were considered to be negligible with respect to hydrostatic weighing error Small differences in per cent body fat values between hydrostatic weighing at residual volume and total lung capacity were also found in a study by Weltman and Katch (1981).

TABLE III

Randomized Block ANOVA Significance Levels

\begin{tabular}{|c|c|c|c|c|c|c|c|c|c|c|c|c|c|c|c|}
\hline & \multicolumn{5}{|c|}{$\begin{array}{l}\text { Residual Volume (RV) Seated } \\
\text { (Pool) }\end{array}$} & \multicolumn{5}{|c|}{$\begin{array}{l}\text { Total Lung Capacity (TLC) Seated } \\
\text { (Pool) }\end{array}$} & \multicolumn{5}{|c|}{$\begin{array}{l}\text { Total Lung Capacity (TLC) Prone } \\
\text { (Pool) }\end{array}$} \\
\hline & $\begin{array}{l}\text { Fat } \\
\%\end{array}$ & $\underset{\mathrm{g} / \mathrm{ml}}{\mathrm{BD}}$ & $\begin{array}{l}\text { FVC } \\
\mathrm{ml}\end{array}$ & $\begin{array}{l}\mathrm{RV} \\
\mathrm{ml}\end{array}$ & $\begin{array}{l}\text { TLC } \\
\mathrm{ml}\end{array}$ & $\begin{array}{l}\text { Fat } \\
\%\end{array}$ & $\begin{array}{c}\mathrm{BD} \\
\mathrm{g} / \mathrm{ml}\end{array}$ & $\begin{array}{c}\mathrm{FVC} \\
\mathrm{ml}\end{array}$ & $\begin{array}{l}\mathrm{RV} \\
\mathrm{ml}\end{array}$ & $\begin{array}{c}\text { TLC } \\
\mathrm{ml}\end{array}$ & $\begin{array}{l}\text { Fat } \\
\%\end{array}$ & $\begin{array}{c}\mathrm{BD} \\
\mathrm{g} / \mathrm{ml}\end{array}$ & $\begin{array}{l}\mathrm{FVC} \\
\mathrm{ml}\end{array}$ & $\begin{array}{l}\mathrm{RV} \\
\mathrm{ml}\end{array}$ & $\begin{array}{c}\text { TLC } \\
\mathrm{ml}\end{array}$ \\
\hline $\begin{array}{l}\text { TLC Prone } \\
\text { (Tank) }\end{array}$ & 0.001 & 0.001 & 0.001 & 0.01 & 0.001 & NS & NS & 0.001 & 0.01 & 0.001 & NS & NS & 0.001 & 0.01 & 0.001 \\
\hline $\begin{array}{c}\text { RV Seated } \\
\text { (Pool) }\end{array}$ & - & - & - & - & - & 0.001 & 0.001 & 0.001 & - & 0.001 & 0.001 & 0.001 & 0.001 & NS & 0.001 \\
\hline TLC Seated & 0.001 & 0.001 & 0.001 & - & 0.001 & - & - & - & - & - & NS & NS & 0.001 & NS & 0.001 \\
\hline
\end{tabular}


The lower body density values and therefore higher per cent body fat values for the residual volume seated (pool) method may have been due to the subjects being apprehensive about going under water at residual volume and therefore not expiring all the air. This thought was reinforced when significant differences were found between all of the methods with respect to forced vital capacity; since this was measured at the time of weighing, the experimenter was able to determine if subjects were inspiring or expiring enough air. The residual volume seated pool method produced the lowest mean forced vital capacity at $4328 \mathrm{ml}$. This was $7.7 \%$ lower than the mean forced vital capacity for the total lung capacity prone tank method, $2.4 \%$ lower than the mean vital capacity for the total lung capacity seated pool method and $4.4 \%$ lower than the mean forced vital capacity for the total lung capacity prone pool method. The lower forced vital capacity could cause an underestimation of residual volume at the time of weighing and thus produce an increase in per cent body fat.

The time period for reading the scale may have contributed to the higher per cent body fat values for the residual volume seated pool method. Subjects were not able to remain underwater at residual volume for as long as at total lung capacity. The shorter time period made it much more difficult to get an accurate scale reading. It is questionable whether hydrostatic weighing at residual volume is accurate for older individuals since this method is difficult even for young people to perform.

The use of total lung capacity seems to be a more comfortable method of hydrostatic weighing and it compares favourably with weighing at residual volume. Weltman and Katch (1981) reported that apprehension associated with weighing was reduced with total lung capacity. Similar findings were evident in this study. All subjects reported difficulty in performing hydrostatic weighing at residual volume.

There were no significant differences in per cent body fat values between the seated or prone lung capacity methods. It appears that either body position can be used accurately as long as lung volumes are measured in the position used for weighing.

There are several favourable characteristics of the total lung capacity prone tank method. First, its use appears to lower the apprehension of the subjects and makes it more comfortable for them. Second, and very important, the use of the respirometer to measure forced vital capacity increases the accuracy of the measurement since the amount of air inspired is recorded and also decreases the need for repeated trials because the experimenter knows if the subject has taken in enough air. Third, the use of total lung capacity gives the experimenter more time to get an accurate scale reading since subjects can remain underwater longer. Fourth, the use of a small tank is much less expensive and takes up less space than larger tanks. This makes it easier for small laboratories to obtain hydrostatic weighing equipment.

\section{References}

Braintree, M. A., 1967. Clinical Spirometry. Warren E. Collins, New York.

Brozek, J., Grand, F., Anderson, J. T. and Keys, A., 1963 "Densiometric analysis of some quantitative assumptions". Ann.N.Y.Acad.Sci. 110: 113-140.

Cournand, A., Baldwin, E. DeF., Darling, R. C. and Richards, D. W., Jr., 1941 "Studies on intrapulmonary mixture of gases. IV. The significance of the pulmonary emptying rate and a simplified open circuit measurement of residual air". J.Clin.Invest. 20: 681-689.

Dahlback, G. O. and Lungren, C. E. G., 1972 "Pulmonary air-trapping induced by water immersion". Aerosp.Med. 43: 768-774.

Etheridge, G. L. and Thomas, T. R., 1978 "The effect of body position and water immersion on lung volumes of women". (Abstract) Med.Sci. Sports 10: 61.

Goldman, R. F. and Buskirk, E. R., Brozek, J. and Henschel, A. (Eds.), 1961 "Body volume measurement by underwater weighing: Description of a method". Techniques for Measuring Body Composition. National Academy of Sciences National Research Council, Washington, D.C.

Katch, F., Michael, E. D. and Horvath, S. M., 1967 "Estimation of body volume by underwater weighing: Description of a simple method". J.Appl. Physiol. 23: 811-813.

Prefaut, C., Lupi, H. E. and Anthonisen, N. R., 1976 "Human lung mechanics during water immersion". J.Appl.Physiol. 40: 320-323.

Robertson, C. H., Jr., Engle, C. M. and Bradley, M.E., 1978 "Lung volumes in man immersed to the neck: Dilution and plethysmographic techniques". J.Appl.Physiol. 44: 679-682.

Thomas, T. R. and Cook, P. L., 1978 "A simple inexpensive method for estimating underwater weight". Br.J.Sport Med. 12: 33-36.

Thomas, T. R. and Etheridge, G. I., 1980 "Hydrostatic weighing at residual volume and functional residual capacity". J.Appl.Physiol. 49: 157-159.

Welch, B. E. and Crisp, C. E., 1958 "Effect of the level of expiration on body density measurement". J.Appl.Physiol. 12: 399-402.

Weltman, A. and Katch, V., 1981 "Comparison of hydrostatic weighing at residual volume and total lung capacity". Med.Sci.Sports Exerc. 13: $210-213$.

Whitfield, A. G. W., Waterhouse, J. A. H. and Arnott, W. M., 1950 "The total lung volume and its subdivisions. A study of physiological norms II. The effect of posture". Br.J.Soc.Med. 4: 86-97.

Wilmore, J. H., 1969a "A simplified method for determination of residual lung volumes". J.Appl.Physiol. 27: 96-100.

Wilmore, J. H., 19679b "The use of actual, predicted and constant residual volumes in the assessment of body composition by underwater weighing". Med.Sci.Sports 1: 87-90.

Wilmore, J. H., Vodak, P. A., Parr, R. B., Girandola, R. N. and Billing, J. E., 1980 "Further simplification of a method for determination of residual lung volume". Med.Sci.Sports Exerc. 12: 216-218. 